\title{
Forces in the vicinity of edge columns in flat-slab floors*
}

\author{
A. S. Hall and B. V. Rangan \\ Contribution by S. G. Gilbert $\dagger$ and A. E. Long $\ddagger$ \\ The Queen's University of Belfast, Department of Civil Engineering
}

The work undertaken by Professor Hall and Professor Rangan in this investigation of edge column behaviour is indeed welcome, as there is a clear need for more research in this area. The careful consideration of the type of model adopted in the experimental programme leading to the choice of a multipanel model, instead of the single-column model, as commonly used, is clearly evident. We accept and endorse the use of the panel model, even though the additional expense and complexity over the isolated single-column model can be large.

The attention to accurate modelling must, however, be continued to the columns themselves. This is particularly so since accurate measurements are to be made of the proportions of the total panel moment entering the column directly by bending. We consider that the omission of the upper columns from the six-column model in the investigation will have a significant influence upon the truth of the picture in relation to the moments transferred from the slab to the column. Professor Hall and Professor Rangan have attempted to achieve representative modelling by increasing the size of the column section beneath the slab to account for no upper column section. However, the occurrence of problematic slab expansion effects will give rise to a misrepresentation of the total column moment unless the upper columns are included.

An extensive programme of work has been already completed ${ }^{(1.2)}$ and work is continuing ${ }^{(3)}$ on the behaviour of edge columns in flat-slab structures. The need for models with carefully controlled boundary conditions was recognized from the outset. The type of model used is shown in Figure I. Throughout the loading, the moment absorbed by each column was recorded by measuring the horizontal thrust at the pinned ends of the columns.

One important finding in the experimental work was that very different amounts of moment were absorbed by the top and bottom columns. This is illustrated in Figure II and it can be seen that the total moment is approximately twice the bottom column

*Pages 19-26 of $M C R 122$.

$\dagger$ Lecturer, Department of Civil Engineering.

$\$$ Professor, Head of Department of Civil Engineering.

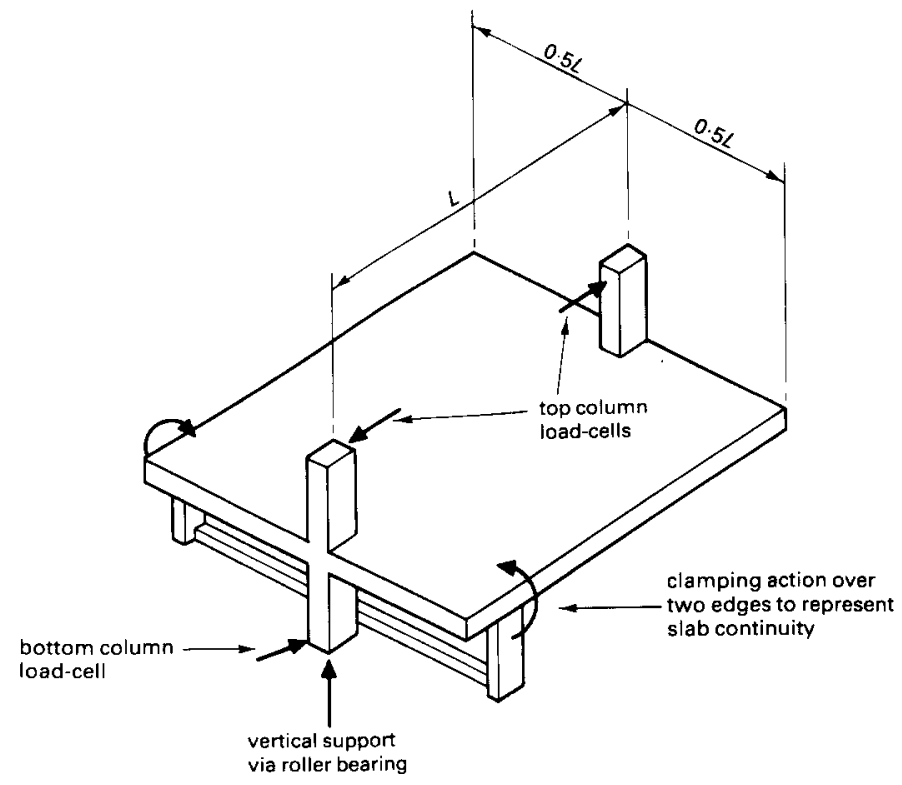

Figure I: Edge column model. 


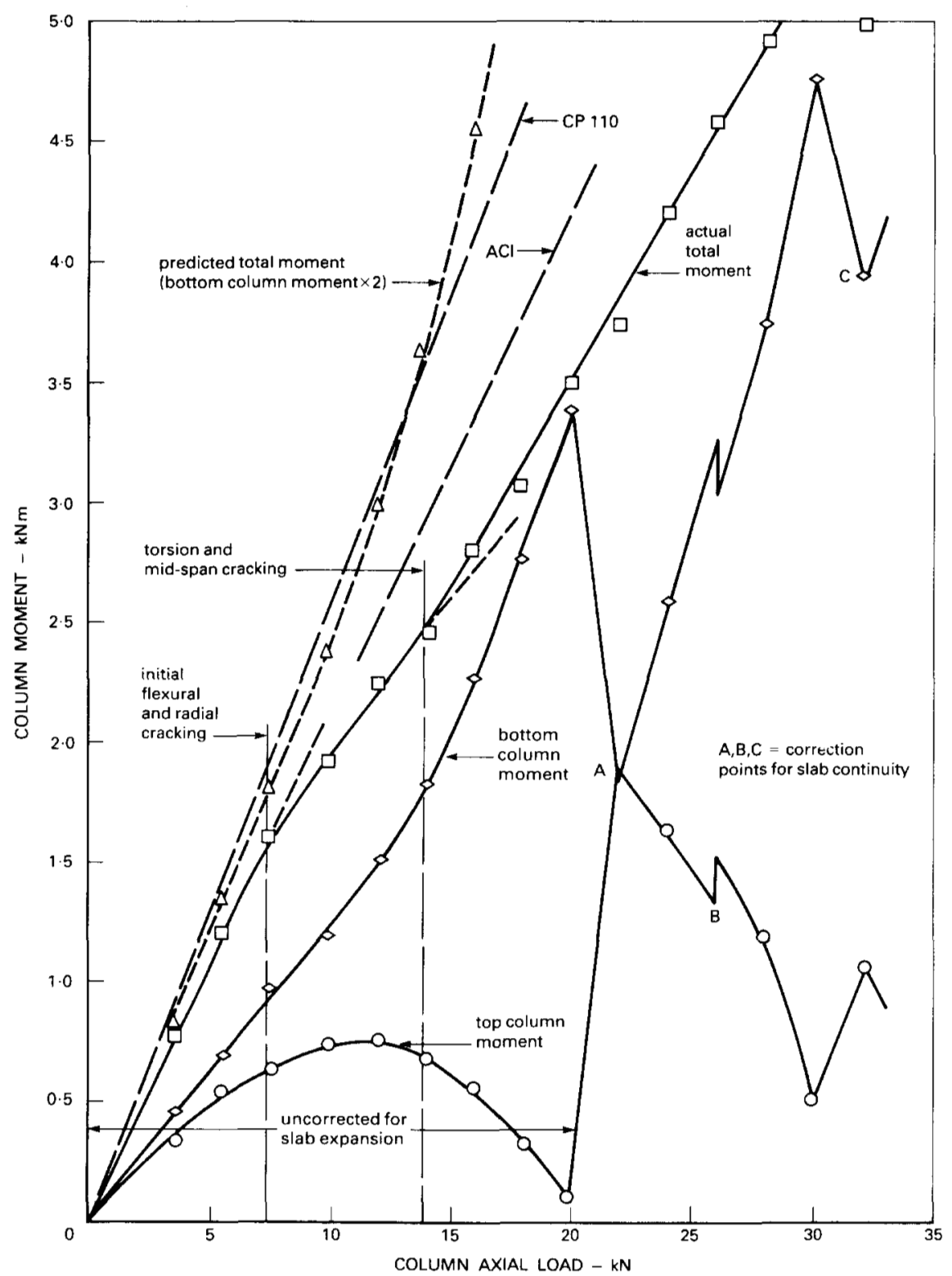

Figure II: Predicted and measured variation of column moment with live load (model 4 of Gilbert and Long's tests).

moment at the early stages of the load history, but later this is certainly not the case.

The near-reversal of the direction of thrust for the upper column is caused by expansion of the slab. The load-cells were relocated at this point and the amount of relocation was set by the magnitude of the slab expansion which had been recorded up to that point. The top load-cell was thus advanced, whilst the bottom one was withdrawn, as shown in Figure III.

This adjustment is seen in Figure II at the $20 \mathrm{kN}$ stage with the two moment curves coinciding at point A. This relocation of the load-cells was repeated at two further stages ( $\mathrm{B}$ and $\mathrm{C}$ ) in order to maintain contact.

It can be seen from the total moment line of Figure II that the erratic effect of the adjustment points on each moment curve is almost entirely eliminated when the two curves are combined. The result of omitting the top column and doubling the bottom column moment is shown plotted on Figure II and, when compared with the actual total moment, can be seen to deviate significantly with much higher moments predicted than actually occurring.

\section{REFERENCES}

1. CIELAND, D, J. and LONG, A. E. An experimental investigation of the behaviour of post tensioned concrete flat-slab structures. Proceedings of an International Symposium on Nonlinearity and Continuity in Prestressed Concrete, Ontario Canada, 1983. Vol. 2. pp. 229-255.

2. GILBERT. S. G. The local strength of flat slabs at edge columns. Thesis submitted to the Queen's University of Belfast for the degree of PhD. 1979. pp. 240.

3. GLASS, C. Reinforced concrete edge column structures. Belfast, The Queen's University of Belfast. 1982. pp. 14. First-year postgraduate research report. 

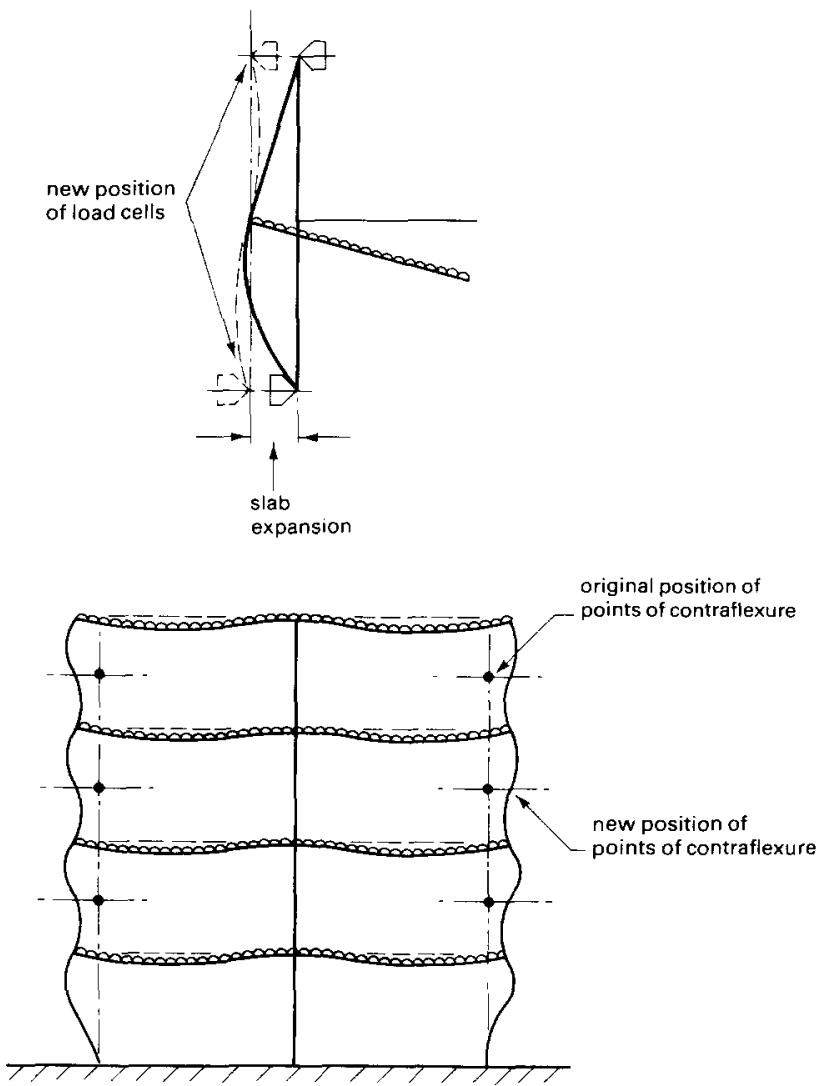

Figure III: Influence of slab expansion upon column support points.

\section{Reply by the authors}

The comments from Dr Gilbert and Professor Long raise some interesting points. The first is the question of boundary conditions, recognized by most investigators as a crucial matter in tests of a partial structure. We were concerned to get the slab boundary sufficiently far from the test column, and this led to a rather massive model. We considered the desirability of extending the columns, specially the test column, to the point of contraflexure above the slab, but the size of the model and the method of support adopted for column A appeared to us to rule out the possibility of the upper column. Reference to the method of support at column A, described in the paper, will indicate the difficulty.

The same support detail made it difficult to compensate for slab expansion. At design ultimate load $\left(9 \mathrm{kN} / \mathrm{m}^{2}\right)$ the slab expansion was about $0.12 \mathrm{~mm}$ and at collapse load $\left(22.5 \mathrm{kN} / \mathrm{m}^{2}\right)$ about $3.0 \mathrm{~mm}$. At first sight it would seem that, since the contraflexure points were not moved outward by corresponding amounts, the support moments would be enhanced in the model. We are dealing approximately with a portal in which the feet are restrained against spreading. This probably would be the case until mid-span yielding occurred, which was at about $11 \mathrm{kN} / \mathrm{m}^{2}$. Thereafter static relationship prevails, the end moment increasing until both end moment and midspan moment reach yield. It would seem that, if our contraflexure point had been moved out, the measured end moment would have been smaller in the low load range and mid-span yielding would have been reached rather earlier. Thereafter, statics would require that the moments be independent of the position of the contraflexure point. At very advanced loads, the support moment and mid-span moment did, in fact, approach the yield values. Clearly these moments were dictated by the reinforcement provided and not by the support details.

We come now to the effect of the lack of the upper column. Dr Gilbert and Professor Long argue that again we have over-estimated the support moment at A by taking $M_{\mathrm{A}}=2 \times M_{\text {lower }}$. It is true that the graphs in their Figure II indicate that the upper column moment is smaller than the lower column moment in the low load range. But we believe that this is largely due to the fact that their contraflexure point was not moved outward at this stage. This would, of course, have just this effect of causing a difference between upper and lower moments.

In summary, it would appear that, up to mid-span cracking, the ratio of end moment to mid-span moment in our results may be somewhat in error, but not at higher loads. Our primary objective was the distribution of $M_{\mathrm{A}}$ and $V_{\mathrm{A}}$ around the column and not the measurement of the absolute values of these quantities, which in design must always be obtained theoretically. 